\title{
Three-dimensional mapping of soil organic matter content using soil type- specific depth functions
}

\author{
B. KEMPEN ${ }^{1}$, D. J. BRUs ${ }^{2} \&$ J. J. STOORVOGEL ${ }^{3}$ \\ ${ }^{1}$ Wageningen University, P.O. Box 47, 6700 AA Wageningen, The Netherlands. bas.kempen@wur.nl \\ ${ }^{2}$ Alterra, P.O. Box 47, 6700 AA Wageningen, The Netherlands. dick.brus@wur.nl \\ ${ }^{3}$ Wageningen University, P.O. Box 47,6700 AA Wageningen, The Netherlands. jetse.stoorvogel@wur.nl
}

\begin{abstract}
In this study depth functions of soil organic matter (SOM) were mapped across a $125 \mathrm{~km}^{2}$ study area in the Netherlands. The mapping method is based on general pedological knowledge about the ten soil types in the area and their associated vertical distributions of SOM. For each soil type the depth function structure was obtained by stacking a subset from five model horizons. Each model horizon had two associated parameters that characterizes the depth distribution of SOM. The depth function parameters were calibrated with data from soil profile descriptions, and then spatially interpolated. Given the soil type at a prediction site, the depth function of SOM was obtained by taking the depth function structure of that soil type and the interpolated, site-specific parameters of the model horizons in that structure. For the study area a soil map was available that represents soil type at any location with a probability distribution. Combining the soil type-specific depth functions with this soil type map resulted in an estimated probability distribution of depth functions at any location in the study area. For the purpose of validation the depth functions were used to compute map the SOM stock for depth intervals $0-30 \mathrm{~cm}, 30-60 \mathrm{~cm}, 60-90 \mathrm{~cm}$. The $R^{2}$ values were $0.75,0.23$, and 0.09 , respectively. Similar results were found in other study areas. This illustrates that there is a general challenge of capturing subsurface variation of soil properties by our pedometric models.
\end{abstract}

Keywords: digital soil mapping, pedometrics, REML, validation, probability sampling

\section{Introduction}

Recently several attempts have been made to use pedometric methods to map the threedimensional variation of soil properties (e.g. Malone et al., 2009; Meersmans et al., 2009; Minasny et al., 2006; Mishra et al., 2009). These attempts typically involve the use of splines or exponential decay functions to describe the variation of soil properties down a profile. Use of these functions is based on the premise that soil properties vary continuously with depth. Although this might be true for relatively undisturbed (uncultivated) soils formed in a homogeneous parent material, in areas where there has been strong human influence on soil formation or where highly contrasting sedimentary layers are present within the soil profile, continuous variation with depth is the exception rather than the rule. In these soils the depth distribution of soil properties often shows both continuous and discontinuous variation, which make splines and exponential decay functions less suitable for modelling depth-wise variation of soil properties. Such soils require soil type-specific depth functions.

Soil maps are available for many areas. These soil maps typically show the spatial distribution of soil types (classes) that are defined, amongst others, on the basis of the presence of diagnostic soil horizons and the properties of soil horizons. Hence, soil type maps can be considered discrete, threedimensional models of soil properties. When such maps are available, then these might very well be used for three-dimensional mapping of soil properties. Soil horizons then act as carriers of soil property information.

The aim of this study is to map the depth functions of soil organic matter (SOM) based on general pedological knowledge about the ten soil types in the study area and the associated vertical distributions of SOM. For each soil type the depth function structure was obtained by stacking a subset from five model horizons. Each model horizon had two associated parameters that characterizes the depth distribution of SOM. The depth function parameters were calibrated with data from soil profile descriptions, and then spatially interpolated using environmental covariates, including the observed soil type at the observation sites. Given the soil type at a prediction site, the 
depth function of SOM was then obtained by taking the depth function structure of that soil type and the interpolated, site-specific parameters of the model horizons in that structure.

\section{Material and methods}

\subsection{Study area and data}

The $125 \mathrm{~km}^{2}$ study area is situated in the province of Drenthe in the northeast of the Netherlands (Fig. 1). The area surrounds the village of Oosterhesselen $(52.75 \mathrm{~N}, 6.72 \mathrm{~S})$. Podzols, plaggen soils, peat soils and hydromorphic, humic earths soils are the major soil types. A dataset was available with 2111 soil profile descriptions in Drenthe (Fig. 1). Ninety-one of these are situated in the study area. The remaining profile descriptions are situated elsewhere in the province at locations with similar soil conditions. The descriptions included the soil type with a profile description including horizon thicknesses and, for most of the horizons, SOM content. Furthermore a raster soil map of $25-\mathrm{m}$ resolution of the province of Drenthe was available that distinguishes ten major soil types (Fig. 1). Soil type is expressed as location-specific probability distributions, as predicted from environmental covariates by multinomial logistic regression (Kempen et al., 2009). Also, 26 grids of 25-m resolution with biophysical predictor variables were available for environmental correlation.

\section{$<<$ FIG 1 NEAR HERE $>>$}

\subsection{Defining the depth functions: structure and parameters}

For each of the ten soil types in the study area a depth function structure was defined that describes the structure of the depth distribution of SOM. To this end we defined five building blocks, which we refer to as 'model horizons':

1. an organic topsoil with constant SOM with depth,

2. a mineral topsoil with constant SOM with depth,

3. an organic subsoil with constant SOM with depth,

4. a mineral subsoil with constant SOM with depth,

5. a mineral subsoil with SOM exponentially decreasing with depth.

For each soil type the depth function structure was obtained by stacking a subset from these five model horizons. Each model horizon has two associated parameters that characterize the depth distribution of SOM. For model horizons 1 to 4 these parameters are the SOM content $\left(\mathrm{kg} \mathrm{m}^{-3}\right)$ and thickness (m). We shall denote these parameters as $C_{i}$ and $d_{i}$ respectively, where $i$ indicates the model horizon. The SOM content in model horizon 5 is modelled by a negative exponential depth function which is defined by parameters $C_{a}$, which is the SOM content at the top of the model horizon, and $k$ $\left(\mathrm{m}^{-1}\right)$ which is the rate of SOM decrease with depth. The depth function for a soil type can then be constructed using the depth function structure and the associated parameters. The depth distribution of SOM described by this function then reflects the distribution one would expect on basis of the profile morphology of the soil type.

\subsection{Mapping the depth functions}

\subsubsection{Derive model horizon parameters from profile descriptions}

The soil profile dataset contains descriptions of almost 11,000 soil horizons. A model horizon number was assigned to each soil horizon based on soil horizon code, geological deposit and soil type. In many profile descriptions a model horizon consists of several consecutive soil horizons. For model horizons 1 to 4, the individual soil horizons that make up the model horizon were aggregated and the parameters SOM content and thickness were computed. The individual soil horizons that make up model horizon 5 were used to fit an exponential decay function with the parameters $C_{a}$ and $k$ using 
non-linear least squares that minimizes the squared differences between the observed and predicted SOM stocks of the individual soil horizons within the model horizon.

\subsubsection{Predict the depth function parameters and construct soil type-specific depth functions}

To map the depth functions for each soil type the parameters of the model horizons used to characterize the depth function structure of that soil type, were interpolated on a 25-m square grid. The parameters were interpolated by universal kriging with variance models estimated by residual maximum likelihood (Lark et al., 2006). The correlated parameters $C_{a}$ and $k$ of model horizon 5 were interpolated by universal cokriging. Instead of calibrating a geostatistical model separately for each soil type, we calibrated a single geostatistical model for each depth function parameter, using the observed soil type (considered to be the true soil type) as a covariate. The biophysical covariates included in the trend parts of the models were selected by ordinary-least-squares regression and the Akaike Information Criterion as a selection criterion.

Using observed soil type as a covariate in the trend parts of the universal kriging models implies that we should also use true soil type for prediction at unsampled sites (Kempen et al., in press). However, true soil type is unknown at unsampled sites but can be represented with a probability model, which is what our soil type map does: at each location it provides a probability distribution of ten soil types. This implies that at each prediction site we require predictions of each of the depth distribution parameters for all soil types. This was accomplished by predicting a given parameter as many times as there are soil types whose depth distribution of SOM is partly described with this parameter. And each time given one of the soil types occurs at each prediction site. The predicted parameters and the soil-type specific depth function structures allow us to construct the soil typespecific depth functions of SOM at each prediction site. By combining the soil type-specific depth functions with the soil type probability distributions from the soil map we obtain a probability distribution of depth functions at each location in the study area.

\subsection{Application and validation of the depth functions}

For validation we used the soil-type specific depth functions to compute the SOM stock $\left(\mathrm{kg} \mathrm{m}^{-2}\right)$ for depth intervals $0-30 \mathrm{~cm}, 30-60 \mathrm{~cm}$, and $60-90 \mathrm{~cm}$. This results in three soil type-specific SOM stocks at each prediction site, i.e. a $25-\mathrm{m}$ pixel. The SOM stock for a pixel is then predicted by:

$$
C_{I}(\mathbf{s})=\sum_{k=1}^{K} p_{k}(\mathbf{s}) C_{I k}(\mathbf{s}),
$$

where $C_{I}(\mathbf{s})$ is the SOM stock at location $\mathbf{s}, p_{k}(\mathbf{s})$ is the probability of occurrence of soil type $k, k=$ $1,2, \ldots, K$, and $C_{I_{k}}(\mathbf{s})$ is the computed SOM stock for a user-defined depth interval for soil type $k$.

The predicted SOM stocks were validated with independent data from 50 sites selected by stratified simple random sampling. At each site soil samples were taken at the three validation depths. The SOM content of each sample was determined with the weight loss-on-ignition method.

\section{Results}

\subsection{Depth functions of SOM for the soil types in the study area}

Table 1 presents the model horizon sequence used to construct the profile depth function of SOM for each of the ten soil types in the study area. It shows that for each soil type two or three model horizons are required to construct the function. For instance, the depth function for soil type $m P$ is given by:

$$
C_{v}(z)= \begin{cases}C_{2} & \text { for } z \leq d_{2} \\ C_{3} & \text { for } d_{2}<z \leq d_{2}+d_{3}, \\ C_{a} \exp \left(-k\left[z-\left(d_{2}+d_{3}\right)\right]\right) & \text { else }\end{cases}
$$


where $C_{v}(z)$ is the SOM content $\left(\mathrm{kg} / \mathrm{m}^{3}\right)$ at depth $z$ from the soil surface, $C_{2}, C_{3}, d_{2}, d_{3}$ are the SOM contents and depths of model horizons 2 and 3. Similar functions were constructed for the other soil types.

\section{$<<$ TABLE 1 NEAR HERE $>$}

\subsection{Spatial prediction of the parameters of the depth functions}

Applying each parameter-specific universal (co)kriging model as many times as there are soil types whose depth distribution is partly described with this parameter, resulted in 50 predicted parameters at each site: 25 soil type-model horizon combinations (Table 1) times two parameters per combination. With these 50 predicted parameters and the soil-type specific model horizon sequences we constructed the depth distribution function for each of the ten soil types at each location in the study area.

\subsection{Application and validation of the depth functions}

Fig. 2 shows the predicted SOM stocks for the three depth intervals. The spatial pattern of each map is clearly controlled by the soil type with the largest probability at a prediction site (Fig. 1b). The average SOM stock in the soils in the study area for the $0-30 \mathrm{~cm}$ layer is $28 \mathrm{~kg} \mathrm{~m}^{-2}$, that of the $30-60$

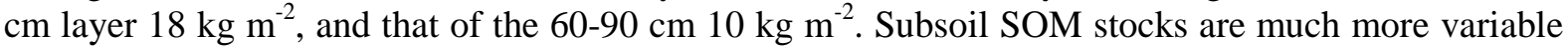
than topsoil stocks. This can be explained by the profile morphology of the soil types, which is much more variable for the subsoils than for the topsoils. The stock for the $0-90 \mathrm{~cm}$ layer ranged between 13 and $182 \mathrm{~kg} \mathrm{~m}^{-2}$. The largest stocks are found in brook-valleys in the eastern and southwestern parts of the study area where peat soils dominate. Here average stock for the $0-90 \mathrm{~cm}$ layer is $140 \mathrm{~kg} \mathrm{~m}^{-2}$ for thick peat soils $(P, m P)$ and $70 \mathrm{~kg} \mathrm{~m}^{-2}$ for thin peat soils $(P Y, m P Y)$. Medium stocks, ranging from $30-$ $50 \mathrm{~kg} \mathrm{~m}^{-2}$ are found in the areas dominated by plaggen soils $(P S)$, podzols $(P Z)$ and earth soils $(E S)$. The lowest stocks $\left(21 \mathrm{~kg} \mathrm{~m}^{-2}\right)$ are found in two drift-sand complexes in the northern part of the study area.

\section{$<<$ FIG 2 NEAR HERE $>>$}

Validation of the predicted SOM stock for the three layers indicated that the accuracy of prediction decreased for each depth interval. For the $0-30 \mathrm{~cm}$ the $R^{2}$ was 0.75 , for the $30-60 \mathrm{~cm}$ layer, 0.23 for the $60-90 \mathrm{~cm}$ layer, and 0.09 for the $60-90 \mathrm{~cm}$ layer. These results agree with findings of Malone et al. (2009) and Minasny et al. (2006) who also reported a decreasing accuracy of prediction with depth for soil organic carbon and available water capacity.

\section{Discussion and conclusions}

This study provides an example how general pedological knowledge about soil profile morphology related to soil types can be used to map depth functions of SOM. This is in contrast with previous studies were one type of function is used (typically a spline or exponential decay) irrespective of soil type and under the assumption that the depth-wise variation of soil properties is only continuous. Furthermore, our approach is closely related to the traditional approach of representing depth distribution of soil properties with representative profile descriptions-the soil horizons of which are characterized by typical values for several soil properties-that are associated to the map units of a soil type map. However, our approach is more flexible than the approach based on representative profile descriptions. The parameter of the functions (e.g. the SOM content and thickness of the horizons) can vary in space, depending on environmental conditions that can be represented by a set of covariates. Additionally, our depth functions are mixed functions that can describe both discontinuous (stepped) and continuous depth-wise variation within a soil profile, which likely better represents the true depth-wise variation of soil properties for most soil profiles in our study area than a complete discontinuous (a soil horizon model) or continuous function (spline or negative exponential). 
Validation with an independent dataset shows that the depth functions provided good estimates of the SOM stock in the upper part of the soil profile. However, the functions performed poorly for the highly variable soil subsurface. Similar results were found in other study areas with different soils and where different functions and different sets of environmental covariates were used to model the depthwise variation of soil properties. This illustrates that there is a general challenge of capturing subsurface variation of soil properties by our pedometric models.

\section{Acknowledgements}

This research is part of the strategic research program "Sustainable spatial development of ecosystems, landscapes, seas and regions" which is funded by the Dutch Ministry of Agriculture, Nature Conservation and Food Quality, and carried out by Wageningen University and Research Centre.

\section{References}

Kempen, B., Brus, D.J., Heuvelink, G.B.M. and Stoorvogel, J.J., 2009. Updating the 1:50,000 Dutch soil map using legacy soil data: A multinomial logistic regression approach. Geoderma, 151(3-4): 311-326.

Kempen, B., Heuvelink, G.B.M., Brus, D.J. and Stoorvogel, J.J., in press. Pedometric mapping of soil organic matter using a soil map with quantified uncertainty. European Journal of Soil Science. doi: 10.1111/j.1365-2389.2010.01232.x.

Lark, R.M., Cullis, B.R. and Welham, S.J., 2006. On spatial prediction of soil properties in the presence of a spatial trend: The empirical best linear unbiased predictor (E-BLUP) with REML. European Journal of Soil Science, 57(6): 787-799.

Malone, B.P., McBratney, A.B., Minasny, B. and Laslett, G.M., 2009. Mapping continuous depth functions of soil carbon storage and available water capacity. Geoderma, 154(1-2): 138-152.

Meersmans, J., van Wesemael, B., De Ridder, F. and Van Molle, M., 2009. Modelling the threedimensional spatial distribution of soil organic carbon (SOC) at the regional scale (Flanders, Belgium). Geoderma, 152: 43-52.

Minasny, B., McBratney, A.B., Mendonça Santos, M.L., Odeh, I.O.A. and Guyon, B., 2006. Prediction and digital mapping of soil carbon storage in the Lower Namoi Valley. Australian Journal of Soil Research, 44: 233-244.

Mishra, U. et al., 2009. Predicting soil organic carbon stock using profile depth distribution functions and ordinary kriging. Soil Science Society of America Journal, 73(2): 614-621.

\section{Tables}

Table 1

Model horizon sequence used to construct the soil type-specific depth distribution functions of SOM and the associated parameters that describe the depth distribution function.

\begin{tabular}{|c|c|c|c|c|c|c|}
\hline \multirow[t]{2}{*}{ Soil type } & \multicolumn{5}{|c|}{ Model horizon } & \multirow[t]{2}{*}{ Depth distribution parameters } \\
\hline & 1 & 2 & 3 & 4 & 5 & \\
\hline $\mathrm{P}$ & $\mathrm{x}$ & & $\mathrm{x}$ & & $\mathrm{x}$ & $C_{l}, d_{l}, C_{3}, d_{3}, C_{a}, k$ \\
\hline $\mathrm{mP}$ & & $\mathrm{x}$ & $\mathrm{x}$ & & $\mathrm{x}$ & $C_{2}, d_{2}, C_{3}, d_{3}, C_{a}, k$ \\
\hline PY & $\mathrm{x}$ & & $\mathrm{x}$ & & $\mathrm{x}$ & $C_{l}, d_{1}, C_{3}, d_{3}, C_{a}, k$ \\
\hline $\mathrm{mPY}$ & & $\mathrm{x}$ & $\mathrm{x}$ & & $\mathrm{x}$ & $C_{2}, d_{2}, C_{3}, d_{3}, C_{a}, k$ \\
\hline $\mathrm{BF}$ & & $\mathrm{x}$ & & & $\mathrm{x}$ & $C_{2}, d_{2}, C_{a}, k$ \\
\hline PZ & & $\mathrm{x}$ & & & $\mathrm{x}$ & $C_{2}, d_{2}, C_{a}, k$ \\
\hline ES & & $\mathrm{x}$ & & & $\mathrm{x}$ & $C_{2}, d_{2}, C_{a}, k$ \\
\hline
\end{tabular}




\begin{tabular}{|c|c|c|c|c|}
\hline PS & $\mathrm{x}$ & $\mathrm{x}$ & $\mathrm{x}$ & $C_{2}, d_{2}, C_{4}, d_{4}, C_{a}, k$ \\
\hline $\mathrm{T}$ & $\mathrm{x}$ & & $\mathrm{x}$ & $C_{2}, d_{2}, C_{a}, k$ \\
\hline $\mathrm{S}$ & $\mathrm{x}$ & $\mathrm{x}$ & & $C_{2}, d_{2}, C_{4}, d_{4}$ \\
\hline
\end{tabular}

\section{Figures}

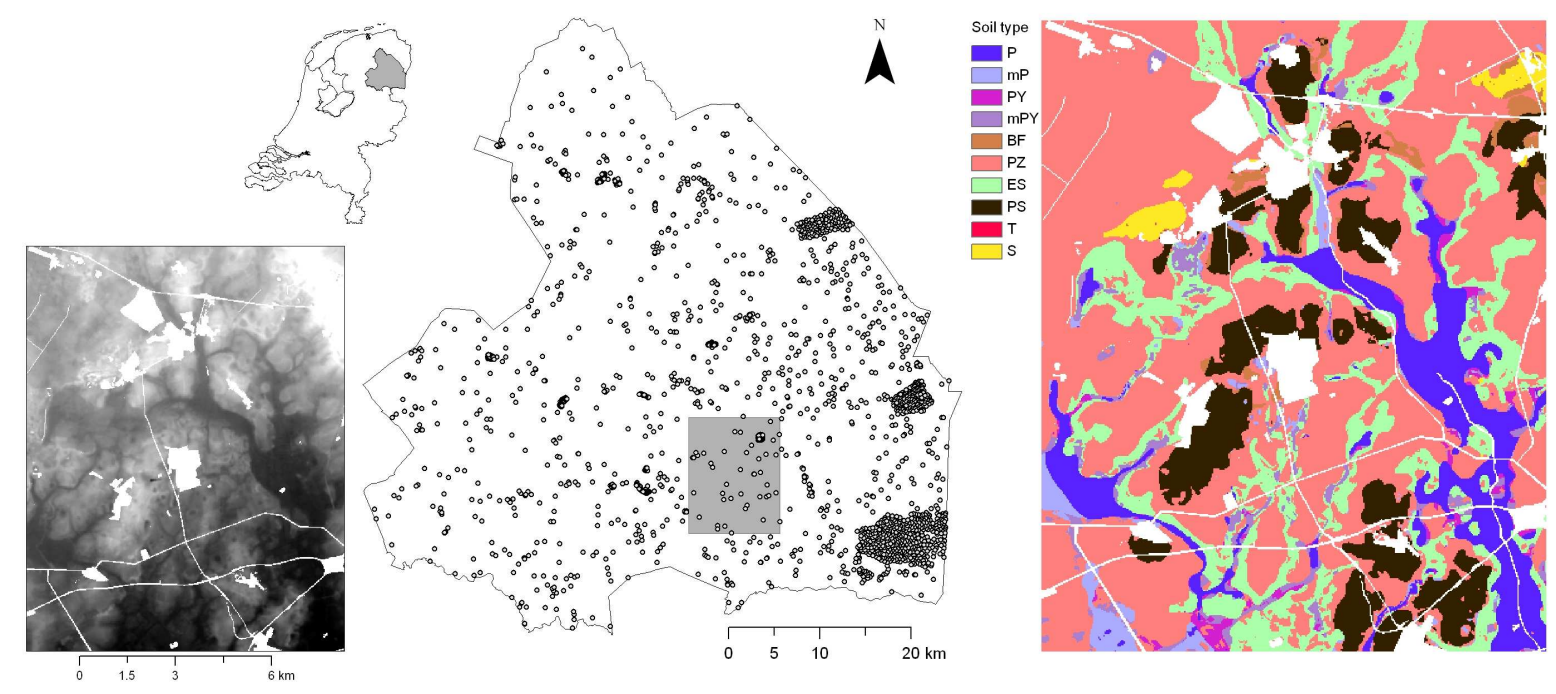

Fig. 1. (a) The study area in the province of Drenthe and locations soil profile descriptions used for calibration of the profile depth functions. The inset with the study area shows the elevation with dark shadings indicating low positions and light shadings the high positions. (b) Soil map of the study area. The depicted soil type at each location is the soil type with the largest probability. $\mathrm{P}=$ thick peat soils (organic layer $>40 \mathrm{~cm}$ ), $\mathrm{mP}=$ thick peat soils with mineral surface horizon, $\mathrm{PY}=$ thin peat soils, $\mathrm{mPY}$ $=$ thin peat soils with mineral surface horizon, $\mathrm{BF}=$ brown forest soils, $\mathrm{PZ}=$ podzols, $\mathrm{ES}=$ hydromorphic earth soils, $\mathrm{PS}=$ plaggen soils, $\mathrm{T}=$ glacial till soils $($ glacial till present within $40 \mathrm{~cm}$ from the surface), $\mathrm{S}=$ sandy vague soils.
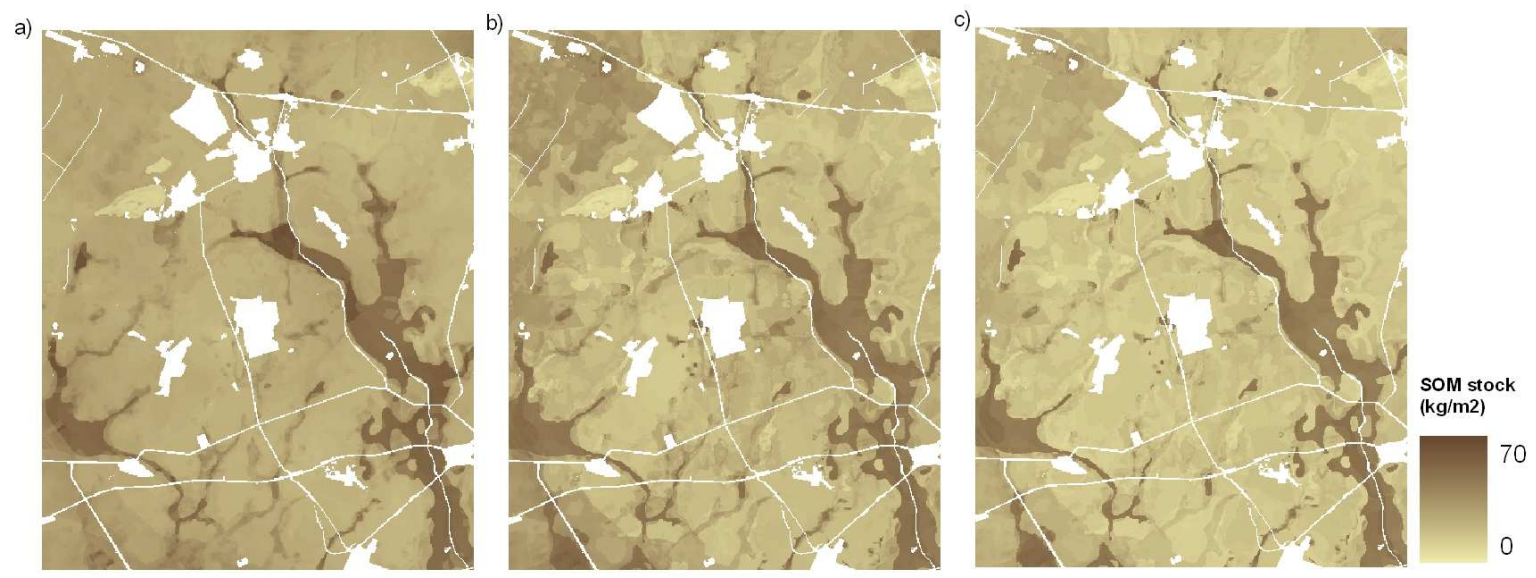

Fig. 2. Predicted SOM stock $\left(\mathrm{kg} / \mathrm{m}^{2}\right)$ at 0-30 $\mathrm{cm}, 30-60 \mathrm{~cm}$ and $60-90 \mathrm{~cm}$ depth intervals. 